Holmes, J., \& Marra, M. (2004). Relational practice in the workplace: Women's talk or gendered discourse? Language in Society, 33(3), PREPRINT.

\title{
Relational practice in the workplace: women's talk or gendered discourse? ${ }^{1}$
}

\author{
"'Nice', 'helpful' and 'thoughtful' are not found on many lists of \\ leadership characteristics" (Fletcher 1999: 115).
}

\section{Introduction}

In her stimulating book Disappearing Acts, Fletcher argues that people with relational skills, people with "emotional intelligence" ("the ability to work effectively with others, understanding the emotional contexts in which work gets done"), tend to "get disappeared from the organizational screen" (1999: 2-3, italics in original). The reason for this disappearing act, she argues, is that relational skills are typically associated with women, and hence devalued: "women are relied on to be the carriers of relational responsibility in society but at the same time are devalued for taking on this role" (1999: 15). Fletcher's book is an account of the many ways in which the relational practices of a group of six women design engineers in a particular organisation were erased or "disappeared" from the organisational record.

In this paper, we explore a variety of ways in which such relational work is manifested in workplace discourse. Focussing on specific instances of relational practice, we illustrate how such support work is often backgrounded or discounted in New Zealand workplaces. 
Holmes, J., \& Marra, M. (2004). Relational practice in the workplace: Women's talk or gendered discourse? Language in Society, 33(3), PREPRINT.

We examine the claim that such work is quintessentially "women's work", arguing rather that relational practice is constructed as "gendered" workplace practice. Indeed, in the light of observations in a wide range of workplace, we suggest that manifestations of RP may differ in distinct communities of practice, and we question the robustness and validity of its equation with feminised discourse.

Our analysis builds on and extends Fletcher's research in a number of ways. Fletcher used observational and interview data to provide a detailed description of relational practices in one particular workplace, an engineering company, and her subjects were exclusively women. Her description covers both verbal and non-verbal behaviour, but her methodology was very dependent on what she personally managed to observe, and on the reliability of people's post-hoc reports about their intentions and achievements. Our study, by contrast, draws on the extensive spoken dataset collected by the Wellington Language in the Workplace (LWP) Project (Holmes 2000a). The Project has been designed to analyse features of effective interpersonal communication in a variety of New Zealand workplaces, and uses a methodology which allows workplace interactions to be recorded as unobtrusively as possible (Stubbe 1998). At the time of writing, the LWP database includes over 1500 workplace interactions collected in many different types of workplace, ranging from government departments, through commercial organisations, to small businesses and factories. This corpus makes it possible to instantiate Fletcher's claim that although relational practice makes an important contribution to constructing and maintaining good relationships at work, it is "disappeared", discounted and ignored. It also enables us to examine the 
Holmes, J., \& Marra, M. (2004). Relational practice in the workplace: Women's talk or gendered discourse? Language in Society, 33(3), PREPRINT.

discourse of both women and men in a range of different workplaces, with very different organisational cultures.

\section{What is relational practice?}

Our analysis of Fletcher's use of the term "relational practice" (henceforth RP) in the workplace suggests that RP has three crucial components:

(i) RP is oriented to the "face needs" of others (Goffman 1974)

(ii) RP serves to advance the primary objectives of the workplace

(iii) RP practices at work are regarded as dispensable, irrelevant, or peripheral

We discuss each of these briefly.

As its name suggests, doing RP at work involves attending to workplace relationships, including both peoples' need to feel valued, their "positive face needs" in Brown and Levinson's (1987) terms, and their "negative face needs", the requirement that their autonomy be respected. RP may entail being friendly or supportive, as well as being polite and considerate. In the workplace context, RP is often appropriately oriented to people's need that their special skills or distinctive expertise be recognised, and it also crucially involves people's need to feel they are valued and important components in a team or a group. 
Holmes, J., \& Marra, M. (2004). Relational practice in the workplace: Women's talk or gendered discourse? Language in Society, 33(3), PREPRINT.

While this is the most obvious and commonsense interpretation of the meaning of RP, ie. any aspect of workplace behaviour oriented to an individual's relationships with work colleagues, Fletcher (1999) defines it more narrowly. In Fletcher's terms, whatever its interpersonal function, RP is also always relevant to, and often inextricably entwined with, the goal of furthering organisational objectives. In other words, in addition to its core relational function, RP simultaneously serves more instrumental or transactional goals. Since, in the broadest interpretation, any behaviour which improves workplace relationships could be regarded as "good for business", there is clearly room for debate here. And Fletcher herself often includes behaviour that is only very indirectly related to furthering workplace objectives. In our view, however, this criterion needs to be applied stringently if the distinctiveness of the concept of RP is to be maintained, and provide insights in the analysis of workplace interaction. We return to and illustrate this point in the analyses below.

Thirdly, despite point (ii), ie. their relevance to workplace objectives, relational practices are typically regarded as dispensable, peripheral, and in some cases even distracting in the workplace. In other words, RP is frequently overlooked, or, if noticed, considered irrelevant, if not counter-productive. Indeed, this off-record status is sometimes explicitly signalled by the use of discourse markers such as to get back to the point, to get back on track, enough digressing, enough (of that). And, less obviously, but more systematically, by markers associated with digressions, such as $\underline{\text { so }}$ (by far the most frequent), anyway,

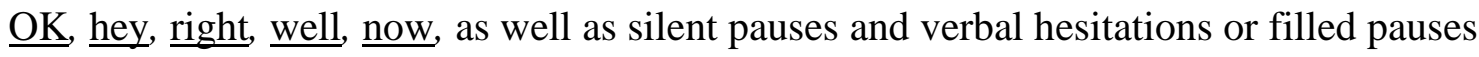
(e.g. um, ㅆ mm) (Schiffrin 1987, Lenk 1998, Marra fc). In one workplace the phrase 
Holmes, J., \& Marra, M. (2004). Relational practice in the workplace: Women's talk or gendered discourse? Language in Society, 33(3), PREPRINT.

moving right along had clearly developed as a routine marker of the end of a digression.

Such discourse markers provide clear evidence to support the claim that strategies used in the pursuit of RP are perceived as off-topic digressions which need to be kept under control.

The relationship between these three features is fluid and often difficult to pin down, as the analysis and discussion below demonstrate. All three points are important in distinguishing RP from other superficially similar types of workplace talk. Subversive humour, for instance, may strengthen solidarity between workmates, but it is often oriented to undermining rather than furthering the organisation's objectives (see Holmes $\&$ Marra 2002). Expressions of approval, on the other hand, very obviously serve workplace objectives and attend to workplace relationships, but are often part of the ratified or "official" workplace discourse, and thus not considered irrelevant. ${ }^{2}$

On the basis of her interviews, observations and shadowing of key personnel, Fletcher's analysis of RP identifies four categories or "themes" which she labels preserving, mutual empowerment, self-achieving and creating team (1999: 48). The first two are somewhat more oriented to transactional or organisational objectives, the second two to personal and interpersonal goals. Preserving focusses on relational practices that are project focussed; they are primarily aimed at advancing the project's objectives. Preserving activities include doing boring, tedious tasks that simply need to be done, even if they are not strictly speaking your responsibility. Mutual empowering is similarly aimed at furthering the project's goals, but it is essentially other-oriented behaviour. It includes 
Holmes, J., \& Marra, M. (2004). Relational practice in the workplace: Women's talk or gendered discourse? Language in Society, 33(3), PREPRINT.

such activities as making connections or putting people in touch with others who can assist them achieve their goals, effective networking for the benefit of others, and "empathic teaching" (Fletcher 1999: 56), namely providing support and guidance in a fashion which is responsive to the addressee's starting point, and even their emotional state.

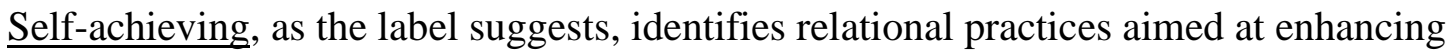
the professional effectiveness of the individual. Fletcher's use of the term covers such behaviours as re-establishing relations with someone after a disagreement in a meeting (1999: 65), and includes reflection aimed at improving understanding of one's own and other's motivations, and of the emotional complexity of situations. Finally, creating team is the term Fletcher uses to discuss activities aimed at "creating the background conditions in which group life [can] flourish" (1999: 74). It includes all the typically unobserved behind-the-scenes behaviours which foster group life and the development of team esprit de corps - activities such as taking the time to listen and respond empathically to non-work-related information, creating opportunities for collaboration and cooperation, interfacing or facilitating productive interaction, and defusing potentially confrontational situations. In this paper, we focus on just two of these categories, namely the ways in which people "create team" and "preserve the workplace enterprise" at work.

Although Fletcher attempts to treat these four categories as mutually exclusive, it is clear that they are often difficult to distinguish. Our experience in analysing workplace 
Holmes, J., \& Marra, M. (2004). Relational practice in the workplace: Women's talk or gendered discourse? Language in Society, 33(3), PREPRINT.

discourse indicates that people are very skilled in exploiting the multifunctional aspects of human communication systems, including language. One utterance typically serves several functions - it may simultaneously advance the project objectives (preserving) and pay attention to the interpersonal dimension of team relationships (creating team), for instance - as indeed the definition of RP presented above suggests. In the next section, we use our data to illustrate Fletcher's claims regarding the complex, and particularly the subtle, ways in which people manage and reconcile the competing demands of transactional and interpersonal objectives in face-to-face workplace interaction.

\section{How is relational practice manifested in workplace discourse?}

In this section, we examine some of the complex ways in which RP is manifested in the New Zealand workplaces we studied. Our analyses of workplace discourse suggest that two fundamental dimensions underlie the many and varied realisations of RP in interaction. Firstly, there is RP which is oriented to constructing and nurturing good workplace relationships, to establishing and maintaining solidarity between team members, and to networking and creating new work relationships. In Fletcher's terms, these are obvious ways of "creating team". Secondly, there is RP which is, to a greater or lesser extent, concerned with damage control: this is RP which is oriented to constructing and maintaining workers' dignity, to saving face and reducing the likelihood of offence being taken, to mitigating potentially threatening behaviour, and to minimising conflict and negotiating consensus. ${ }^{3}$ While damage control strategies are most obviously 
Holmes, J., \& Marra, M. (2004). Relational practice in the workplace: Women's talk or gendered discourse? Language in Society, 33(3), PREPRINT.

oriented to "preserving" and protecting the workplace enterprise, our conception of RP emphasises how both sets of strategies may contribute to this goal. In what follows, we provide examples of some of the diverse manifestations of each of these dimensions of $\mathrm{RP}$ in workplace discourse.

\section{Creating team}

People at work use a wide variety of discourse strategies to construct and maintain good relations with their co-workers. These include engaging in small talk and social talk (Holmes 2000b), introducing humour into workplace (Holmes 2000c), telling entertaining stories or anecdotes (Holmes \& Marra 2001), and paying compliments or giving approval. In this section, we provide examples of these varied manifestations of $\mathrm{RP}$, indicating how they fulfil the three criteria described above. We focus on strategies that are stereotypically associated with "women's language" or "girltalk" in order to lay the foundation for a discussion of the "gendered" nature of RP below.

\section{Small talk and social talk}

Small talk and social talk at work clearly serve the function of establishing and nurturing workplace relationships; and the label "small talk" itself explicitly signals the perceived status of this type of talk as trivial, and irrelevant to serious workplace business. ${ }^{4}$ In fact, most social and interpersonal talk in the workplace is typically discounted, or in 
Holmes, J., \& Marra, M. (2004). Relational practice in the workplace: Women's talk or gendered discourse? Language in Society, 33(3), PREPRINT.

Fletcher's terms "disappeared", from the organisational record. Thus small talk clearly meets two of the criteria for RP. Not all social talk at work, however, meets the third criterion, namely, serving to advance the primary objectives of the workplace, except in the rather indirect respect mentioned above that fostering good relationships at work generally contributes to achieving workplace goals. Nevertheless, we did identify in our data set a number of interesting instances of social talk which met this third criterion.

\section{Example $1^{5}$ Impact of baby}

Context: Peg and her manager belong to a large commercial organisation. They are chatting at the end of a meeting of their project team. Peg is pregnant.

1. C: how is the baby

2. P: [drawls]: good: still just a baby though

3. C: right not a boy baby or a girl baby

4. P: no can't tell /it's legs crossedl

5. C: /haha you gonna have to wait....

6. are you feeling tired

7. P: yes but I just think it's summer too

8. because I didn't you know because been in summer

9. $\quad \cos$ I wasn't pregnant last time or AS pregnant in the summertime

10. so it was much easier cos I didn't know +

11. um I had help (until) December last time (so it was easier)

12. C: hey you you're hoping you're gonna work [drawls]: through: /(what )। 
Holmes, J., \& Marra, M. (2004). Relational practice in the workplace: Women's talk or gendered discourse? Language in Society, 33(3), PREPRINT.

13. P: /well + my $\backslash$ plan is is to work full time up until the end of May

14. C: right

15. P: and then come back as we need as I'm needed after that

16. just dependent on what happens with Daisy and Matt's group ......

This conversation moves very clearly from social talk to work talk, from a discussion of non-work topics, Peg's baby's health and gender (lines 1-5) and Peg's health (line 6-11), to the discussion of the impact of her pregnancy on her contribution to the organisation (lines 12-16). Peg's manager is clearly engaging in RP; the expressions of interest about the baby and concern for Peg's general condition are classic (positive) face attention strategies, constructing and nurturing good workplace relationships. However, the discussion also addresses the implications of this information for the project team's objectives. Although the content of line 12 (you're hoping you're gonna work through) could be simply a further expression of interest, Peg's response (lines 13,15-16) indicates that she orients to her manager's comment as transactional rather than interpersonal in intent. This is classic RP and we have many more very similar examples in our data from a wide range of different workplaces (see, for example, the conversation between a personal assistant and manager in a government organisation concerning taking time off in the school holidays in Holmes 2000b: 53).

In terms of gender, it is worth considering whether such talk instantiates stereotypically feminine discourse. While the non-work topic of an expected baby in example 1 
Holmes, J., \& Marra, M. (2004). Relational practice in the workplace: Women's talk or gendered discourse? Language in Society, 33(3), PREPRINT.

undoubtedly comprises stereotypical women's talk, it also provides an entrée to explore the consequences for the organisation of Peg's potential unavailability, a concern which is much less obviously feminine. Is the manager skilfully managing the discourse for this purpose? We return to this gender issue in the discussion below.

In a similar fashion, discussions of leave and holidays frequently move very subtly from plans for how the recreational time will be spent to discussion of how the organisation will cope with the person's absence, skilfully serving both interpersonal and transactional goals. Off-topic social talk serves as a means of addressing an issue of direct concern to the progress of a project or the smooth running of a department. One interesting fact about such conversations is that they are consistently located at the boundaries of workplace interaction. They typically occur at the ends of meetings, often as people are walking out of a room, and even during social breaks. In other words, these conversations usually occur "off the record"; the transactional goal is achieved "by the way" during a conversation which both parties would typically consider as irrelevant small talk or social talk. They clearly fit the criteria for RP outlined above and they illustrate the subtle ways in which apparently irrelevant workplace discourse can serve organisational goals.

\section{Positive humour}

Humour in the workplace is a very obvious candidate for inclusion in a review of strategies which qualify as manifestations of RP. Humorous comments are typically 
Holmes, J., \& Marra, M. (2004). Relational practice in the workplace: Women's talk or gendered discourse? Language in Society, 33(3), PREPRINT.

intended to entertain and amuse colleagues, to "create team" by constructing and strengthening workplace solidarity and collegial relationships. ${ }^{6}$ And, like social talk, of which it is often a component, humour also qualifies as typically irrelevant to the main objectives of the workplace. It is always "de trop" or dispensable in the strictest sense, since the contribution made by humorous behaviour or discourse at work falls squarely in the area of interpersonal relationships. We have discussed these characteristics of workplace humour at length elsewhere, and provided many and varied examples from a range of workplaces (see Holmes 2000c, Holmes \& Marra 2002, ip).

Example 2 illustrates humour which is tightly integrated into talk which contributes to the goals of the team. It centres around the need to coordinate the taking of annual leave to ensure minimum negative impact on the work project. $^{7}$

\section{Example 2 Panic early}

Context: Planning meeting of a group of colleagues. S. is the section manager. At this point they are discussing leave plans.

1. H: people might have to take some leave by that stage

2. as well with this sort of panic before the end of November

3. W: oh I'm saving up all mine [laughs]

4. S: well people could panic early [laughs]

5. [general laughter]

6. H: never happens 
Holmes, J., \& Marra, M. (2004). Relational practice in the workplace: Women's talk or gendered discourse? Language in Society, 33(3), PREPRINT.

7. [general laughter]

8. S: well the HR coordinators might crack the whip

9. $\quad$ /so that people panic early yes $\$

10. T: /I planned to panic early by taking the school holidays off

11. but that didn't work [laughs]

12. W: /[laughs]

13. B: /sol can we- can I suggest the dates you're not available from say the fifteen of November

The manager suggests it may be useful to "panic early" (line 4), a humorous way of indicating the importance of planning ahead, and something of a contradiction in terms, since the notion of panic is almost inextricably tied to last minute pressures. The group clearly share a common reaction to the notion, and this is a good example of them "doing collegiality" through humour. The humorous scenario is interactively achieved or jointly constructed: H's comment (line 6) and T's contribution (lines 10-11) both build on the manager's humorous suggestion, which is further elaborated in lines 8-9.

This example illustrates how humour provides an ideal means of doing RP at work. Firstly, the very collegial and cooperative structure of the talk, as well as its function of providing amusement, support the argument that it is contributing to the development of workplace solidarity. Secondly, the discussion is obviously of relevance to achieving the group's workplace objectives. And thirdly, it is clear that the content of this exchange 
Holmes, J., \& Marra, M. (2004). Relational practice in the workplace: Women's talk or gendered discourse? Language in Society, 33(3), PREPRINT.

could have been communicated without any humorous component; in other words, the humour is strictly speaking irrelevant and superfluous.

Example 3 illustrates a more sophisticated instance of RP manifested in a humorous interchange. Three colleagues are discussing the fact that eliciting a response to a proposal or request for advice is a slow process in their organisation.

\section{Example 3 The Len Factor}

Context: a meeting of three work colleagues in a government department

1. A: /( talk with)\let's go let's go and talk to someone else

2. we'll get a COMpletely different story about what to do

3. S: $[$ laughs $] /[$ laughs $] \backslash$

4. A: /you know the whole thing will just sort of $/$ grow in/to al soap opera

5. V: /[laughs] yeah।

6. this is Christina came up with a good phrase before

7. I think we should just adopt it the of- in in the office

8. she said you need to account for the Len factor

9. S: [gasps] /the Len factor I love it oh brilliant

10. V: [laughs] /laughs]

11. S: /I think Alex and I were talking about the Len factor yesterday [laughs]

12. /[laughs] oh yeah\

13. V: /exactly thank you $\mathrm{S}$ that's great। 
Holmes, J., \& Marra, M. (2004). Relational practice in the workplace: Women's talk or gendered discourse? Language in Society, 33(3), PREPRINT.

We here witness, or rather overhear, the creation of a piece of workplace jargon "the Len factor", a humorous instance of in-house shorthand which becomes well-established in this workplace. In lines 1-4, A describes how the same problem frequently elicits completely different advice from different individuals. Then $\mathrm{V}$ informs the others of a phrase, "the Len factor", coined to describe the unavoidable delay which must be built into any estimate of how long obtaining a response will take. Len is a colleague who is well known for always seeing difficulties and identifying problems, rather than facilitating the speedy resolution of an issue or the smooth passage of a proposal. "The Len factor" is an amusing succinct means of referring to the inevitable delays such behaviour generates.

This is canonical RP: the three colleagues are clearly on the same wave-length, the humour contributes to their sense of belonging to the same team; they are discussing an issue of obvious relevance to their workplace objectives; and the humour is strictlyspeaking dispensable. It is a particularly telling example because the jargon phrase thus created continues to generate (strictly irrelevant) humour whenever it is used, while succinctly summarising an important step which needs to be taken into account in any planning process.

Is humour gendered discourse? And if so which gender is it associated with? On the one hand there is research evidence that women at work are regarded as lacking a sense of humour (Lakoff 1975, Cox, Read \& van Auken 1990, Crawford \& Cressley 1991, 
Holmes, J., \& Marra, M. (2004). Relational practice in the workplace: Women's talk or gendered discourse? Language in Society, 33(3), PREPRINT.

Crawford 1995). On the other hand, whenever we discuss such research, especially with working New Zealand women, they are at least sceptical and often incredulous. And our own analyses of humour in the workplace provide substantial evidence that in a range of workplace contexts women contribute at least as much humour as men (Holmes, Marra \& Burns 2001, Stubbe, Holmes, Vine \& Marra 2000). Again this is an issue we will return to below.

\section{Off-record approval}

A third strategy for creating team or constructing good work relationships is the very obvious one of giving approval. There were many examples of this strategy in our data, especially from superiors to subordinates, and between colleagues of equal status, though in line with the egalitarian values of New Zealand culture (in which tall poppies are not tolerated and praise is often regarded with suspicion), they are typically brief and low key (eg. great, good work, fine, nice one). The instances we are concerned with here, however, are instances where approval was provided indirectly or off-record, where it was in a sense "unofficial". These are instances of approval which qualify as RP; they are invisible, overlooked, and perhaps undervalued examples of individuals providing positive feedback to others in the workplace.

Like the instances of social talk discussed above, instances of approval which function as RP tended to occur at the peripheries or boundaries of workplace interaction. They were 
Holmes, J., \& Marra, M. (2004). Relational practice in the workplace: Women's talk or gendered discourse? Language in Society, 33(3), PREPRINT.

components of interaction which were literally "off-record" in meetings, for instance, not recorded in the minutes, and often occurring before a meeting started or after it finished. Throwaway comments such as nice job, given by one colleague to another in the corridor after a presentation, for instance, or you nailed them following a confrontational meeting illustrate remarks which go formally unrecorded, but which contribute to team spirit.

Example 4 illustrates the rather more complex and challenging situation of a subordinate giving positive feedback to a superior. Examples of this kind of RP in our data demonstrate great skill on the part of the subordinate, since, as noted above, it is crucially important to avoiding accusations of flattery or "crawling". ${ }^{8}$

\section{Example $4 \quad$ J's work experience}

Context: Beginning of a meeting at a big commercial organisation. $\mathrm{J}$ is the Project leader and Chair and has arrived first. B is next to arrive and they are chatting as they wait for the rest of the team members to arrive.

1. B: where did you learn sort of project management type of skills

2. J: oh I never did

3. B: cos you seem really good at it and awfully

4. J: I've just winged it

5. B: confident

6. J: um I -I started in engineering and I guess that

7. they're fairly large pro- you know they're they're quite finite bites 
Holmes, J., \& Marra, M. (2004). Relational practice in the workplace: Women's talk or gendered discourse? Language in Society, 33(3), PREPRINT.

8. like each [local centre] is a project on its own

9. but um so you've got to you do a construction plan for it

10. so that you know the first /thing $\mid$

11. B: $/ \mathrm{mml}$

12. J: that the foundation goes in first the walls go up second (you know) .......

In this canonical position for small talk, B introduces the topic of Sandy's management skills and proceeds to pay a compliment you seem really good at it and awfully confident (lines 3,5 ). In this position, before the start of a meeting, their talk is clearly off-record. Indeed it is unlikely B would have made these comments once others had arrived. This is a nice example, then, of RP: an off-record, supportive comment which clearly relates to the goals of the organisation. Appreciation, such as this, even (or perhaps especially) from a subordinate, is likely to encourage Sandy to continue to perform well and continue to practice good management skills. Yet, by virtue of its position and off-record status, the approval has no formal or unofficial weight.

Similar examples occur elsewhere throughout our data. In one workplace a team member who had been working on a relatively minor aspect of the organisation's work for some time, expressed appreciation to the $\mathrm{CEO}$ for explicitly recognising the value of this work by including reference to it in the agenda of a meeting of high status managers. In another organisation, a wry comment we missed you from a subordinate to their manager returning from leave, served primarily as a way of introducing a jocular complaint about the deputy who had temporarily replaced the manager. In all these cases, while the 
Holmes, J., \& Marra, M. (2004). Relational practice in the workplace: Women's talk or gendered discourse? Language in Society, 33(3), PREPRINT.

expression of appreciation is indirectly achieved, it nevertheless functions to attend to workplace relationships, thus maintaining the team momentum on the project.

Like small talk, compliments and praise are strongly associated with women's talk; and there is evidence that in many contexts women do indeed provide more positive comments than men (eg. Holmes 1998, 1995, Herbert 1990, Johnson \& Roen 1992). Our workplace data of actual recordings in a number of very different organisations, throws light on how such patterns may develop so that stereotypical gendered identities are constructed and fostered within particular communities of practice. We return to this point in the discussion of gender and relational practice below. We turn now to examples of strategies which preserve the workplace enterprise, and further workplace goals, predominantly through their orientation to face protection - one could regard them as damage control strategies.

\section{Damage control}

Strategies which nurture positive relationships among work mates and colleagues illustrate one dimension of RP. Their converse, and just as important in furthering workplace goals, are strategies which minimise sources of conflict between work mates, and attend to the maintenance of workers' dignity. A good deal of the discourse in some workplaces is oriented to avoiding conflict, to minimising the chances of a breakdown in workplace relationships, and to negotiating agreement. This kind of discursive behaviour 
Holmes, J., \& Marra, M. (2004). Relational practice in the workplace: Women's talk or gendered discourse? Language in Society, 33(3), PREPRINT.

contributes to preserving the workplace relationships which are essential to the advancement of the organisation's objectives. In our data, some of the most obvious ways in which these goals were achieved were through strategies of mitigation.

Individuals concerned with achieving their workplace objectives would seek ways of mitigating negatively affective speech acts such as disagreements, refusals, complaints and criticisms.

We here illustrate just two such strategies, indicating how they fulfil the three criteria described above: firstly, we consider skilful, off-record, facilitative work, and secondly, the use of humour to mitigate face threatening or even face attack acts, both used in the interests of avoiding conflict, nurturing important team relationships, and thus furthering the organisation's goals.

\section{Covert facilitation}

It is possible to identify a range of different instances in our workplace data, where individuals take steps to manage potentially conflictual situations, to pour oil on troubled waters, or to anticipate problems and head off possible challenges (see, for example, Holmes \& Stubbe 2001). Two brief examples must suffice here. In example 5, S reports eliciting information which suggests the project team should proceed gently with the next stage of their project.

\section{Example 5 Corridor work}

Context: project team meeting in large commercial organisation. 
Holmes, J., \& Marra, M. (2004). Relational practice in the workplace: Women's talk or gendered discourse? Language in Society, 33(3), PREPRINT.

1. S: um I've had a few discussions with people er in the corridor

2. which [quietly]: is where I do my best work:

3. um /+ people are \saying that no

4. B: /(if we can get your attention)।

5. S they're er they're not confident that on day one they're gonna be able to go

6. and and I think it's a little bit of-

7. C: people are saying they're not confident

8. S: yeah and I had a discussion with someone who said

9. you know that er it it's taken two years to get up to speed ...

10. and I just wonder um hopefully that we can channel through the different

11. having the team leaders here and stuff

S here describes picking up rumbles of concern among those responsible for actually implementing the project which this team is managing. This is precisely the kind of invisible off-record discussion which Fletcher (1999) emphasises as canonical RP: the relational work involved in anticipating problems, having antennae tuned for potential disaster or failure, and thus "preserving" the project and increasing its chances of success. S's observations lead to a discussion of what can be done to re-assure and support the implementation group. 
Holmes, J., \& Marra, M. (2004). Relational practice in the workplace: Women's talk or gendered discourse? Language in Society, 33(3), PREPRINT.

Such "discussions in the corridor" are classic instance of RP: they provide a means for those most directly involved to express their worries about the project time-table. S's covertly facilitative behaviour thus serves to warn those higher up the authority structure of potential implementation problems, so that preventative action can be taken.

The second instance, example 6, illustrates a project manager setting up the department manager to provide approval for a valuable contribution to the discussion and the project. The project manager is providing a report on exactly what the various team members have accomplished since the last meeting.

Example 6 Vita merits praise

Context: Large project team meeting in commercial organisation. Project manager is reporting on project progress to department manager.

1. J: um service levels team to produce a strategy document they've done +

2. um Vita was to meet with IS to determine er

3. an implementation plan for the recording device

4. V: yes done it +

5. J: [parenthetical tone] Vita's done a um work plan just for that

6. /um implementation $\backslash$ and that

7. C: great /that'll make the plan easierl

8. J: we can feed /(out what) you wantl

9. V: /haven't actually (heard anything ...) 
Holmes, J., \& Marra, M. (2004). Relational practice in the workplace: Women's talk or gendered discourse? Language in Society, 33(3), PREPRINT.

10. J: Vita's going to meet with Stewart

11. to determine how 0800 numbers come in to the call centre

In lines 1-3, the project manager reports on what the team agreed Vita should do by this meeting, and in line 4, Vita confirms that she has indeed accomplished the specified task. Since the Department manager makes no immediate response, J proceeds in lines 5-6 (Vita's done a work plan just for that implementation) to "prime" C to provide positive feedback to Vita. C responds appropriately in line 7 with a positive and appreciative comment, and $\mathbf{J}$ then continues with the next item. The facilitative move is made extremely discreetly, and the manager picks up J's cue without missing a beat. This is excellent RP - subtle, backgrounded, relational work, attending to workplace relationships in the interests of the project's progress.

In another organisation where we recorded extensively, the manager of one section regularly engaged in a good deal of off-record RP around the edges of the more on-record transactional interactions which dominated the official record of the department's outputs. The skilful negotiation of consensus which is documented in detail in Holmes (2000d) includes many instances of covert facilitative strategies used to minimise conflict.

Closely related are examples where one team member defends another from face attack, often in the form of teasing, or jocular abuse, by other team members. Such protective behaviour may function to subtly underline the importance of good team relations in furthering project goals; the covert message is "don't undermine team members - we all 
Holmes, J., \& Marra, M. (2004). Relational practice in the workplace: Women's talk or gendered discourse? Language in Society, 33(3), PREPRINT.

need each other". Indeed humour can itself be used as a damage control strategy, as we illustrate in the next section.

\section{Mitigating humour}

Humour is a very flexible communication strategy. As illustrated above, it is an effective means of creating team, but it can also be used to attenuate the force of negatively affective speech acts such as disagreements, refusals, complaints and criticisms. Humour can soften the impact of a face threatening act (FTA) such as a directive (Brown \& Levinson 1987: 124, Holmes 2000c), and take the sting out of a refusal (Holmes \& Stubbe 2001) or a criticism (Holmes \& Marra 2002). Humour was used extensively in this way in our data. There are, for example, critical comments about the time it takes someone to read a document, or take notes, or the length of something they have written, all of which are attenuated with ironic humour. There is a humorous exchange about the "final" status of a document which has been back for revision many times (this is THE final version). And there are many jocular insults which serve to express irritation or dissatisfaction in an acceptable manner. ${ }^{9}$ Here we analyse just one example to illustrate how humour may be employed as a canonical RP strategy.

Example 7: No screendumps ${ }^{10}$

Context: regular weekly meeting of project team in large white collar organisation.

$1 \mathrm{H}: \quad$ look's like there's been actually a request for screendumps 
Holmes, J., \& Marra, M. (2004). Relational practice in the workplace: Women's talk or gendered discourse? Language in Society, 33(3), PREPRINT.

2 I know it was outside of the scope

3 but people (will be) pretty worried about it

4 C: $\quad$ no screendumps

5 M: we-

6 C: no screendumps

$7 \quad$ P: $\quad$ [sarcastically] thank you Chris

$8 \quad \mathrm{C}: \quad$ /no screendumps $\backslash$

$9 \quad$ M: /we knowl

we know you didn't want them and we um er /we'vel

$10 \mathrm{C}: \quad /$ that does not $\backslash$ meet the criteria

[several reasons provided why screendumps should be allowed]

$11 \mathrm{C}$ : thanks for looking at that though

12 S: so that's a clear well maybe no

13 C: it's a no

14 S: it's a no a royal no

15 C: did people feel disempowered by that decision

16 P: [sarcastically] no

The team has received requests to allow people to print from the computer screen (i.e. to "screendump"). The section manager clearly opposes this proposal, with an explicit prohibition no screendumps (line 4). The rest of the team are unhappy with this, and they proceed to provide reasons why screendumps should be permitted, but the manager over-rides their opposition by simply repeating no screendumps. Humour is then co- 
Holmes, J., \& Marra, M. (2004). Relational practice in the workplace: Women's talk or gendered discourse? Language in Society, 33(3), PREPRINT.

opted as a damage control strategy to preserve good working relations in the face of the peremptory veto. P's sarcastic thank you Chris (line 7) provides an initial tensionbreaker, and S's suggestion that Chris may be wavering so that's a clear well maybe no (line 12) is humorously internally contradictory. It leads Chris to restate the position quite explicitly it's a no (line 13), and again $\mathrm{S}$ defuses the tension with a humorous hyperbolic comment it's a no a royal no (line 14), echoing a reference to an earlier humorous episode in which Chris's status had been satirised as a member of the royal family. Finally, Chris too contributes to the defusing of the tension with a humorous comment which draws explicit attention to feelings which people usually conceal in a business context did people feel disempowered by that decision (line 15).

The humour in this short excerpt nicely illustrates all three aspects of RP. Its function is to help manage the conflict and to preserve the group relationships, as well as maintain the longer-term project goals. While $\mathrm{P}$ and $\mathrm{S}$ use light satirical comments to defuse the sting of Chris's refusal, the content of their contributions (a sarcastic expression of appreciation, and a satirical request for clarification of something which was crystal clear) also imply acceptance of Chris's intent. These humorous comments could strictly speaking be regarded as a digression from the team's core business, since they delay progress with the next agenda item. They are certainly off-record and technically irrelevant, though of course, like all effective RP, the invisible work they do is crucial to the long term health of the project and the project team's relationships.

Damage control is most certainly considered a distinctive feature of women's talk in the language and gender literature. ${ }^{11}$ There is extensive evidence that women tend to use a 
Holmes, J., \& Marra, M. (2004). Relational practice in the workplace: Women's talk or gendered discourse? Language in Society, 33(3), PREPRINT.

wide range of both facilitative strategies and mitigating devices to attenuate negatively affective speech acts and maintain good relations (see, for example, Holmes 1995, Coates 1996). In the next section, we consider the extent to which the use of such RP strategies in the workplace can be considered to be predominantly aspects of "women's work".

\section{Relational practice, gender and workplace culture}

Fletcher's analysis of RP focusses on women: firstly, she argues that RP is "women's work", and secondly, her subjects were six professional women in a predominantly male workplace, an engineering firm. The data she describes from her observations and interviews was collected from her women subjects, and it clearly supports her view that $\mathrm{RP}$ is undervalued and invisible, and even "disappeared": ie discounted as unimportant and irrelevant to the organisation's core business.

The material we have collected, and from which we have illustrated in this paper, is taken from a wide range of workplaces, and the recordings involve both women and men. Our analysis clearly demonstrates that RP is by no means the sole prerogative of women. Readers may have noticed that we used a variety of strategies to avoid indicating the gender of the participants in the material analysed above. We avoided names and singular pronouns, and where names were used, unisex pseudonyms were selected. ${ }^{12}$ In more than half of our examples, the RP was being undertaken by a man, while the manager, or the 
Holmes, J., \& Marra, M. (2004). Relational practice in the workplace: Women's talk or gendered discourse? Language in Society, 33(3), PREPRINT.

person wielding most authority in the situation was a woman. Clearly RP is not undertaken only by women - it more closely reflects power relationships than gender identity. As Beck (1999: 200) suggests, feminised discourse practice "could be seen as an expression of women's relative lack of societal power" rather than a "characteristic of womanhood". The fact that the relevant examples involve damage control strategies rather than solidarity oriented strategies supports this interpretation, but should not be over-emphasised, since it would have been possible to find examples in all categories with men or women as the proponents of the RP.

So is RP undertaken more often by women than men in the workplace? Or is it the domain of the powerless and those with less status in the organisational hierarchy? This "essentialist" question raises a number of issues, of course, some of which lie right at the heart of gender analysis. One is a simple practical matter: it is impossible to document all instances of RP. Many are non-verbal, and, by their very nature, most instances go undocumented and unseen. As we have repeatedly noted, RP is invisible, off-record, behind-the-scenes support work, which is regarded as irrelevant and dispensable. Counting instances is not a serious option. But, more importantly (as noted and extensively illustrated in Holmes \& Meyerhoff fc a), "the field has moved well beyond descriptions of (perceived or actual) differences between men's and women's speech, or finger-pointing that maps power hierarchies with gender hierarchies." Current research is rather concerned with analysing the complex and skilful ways in which people at work accomplish different aspects of their workplace identity (Holmes 2000d, Holmes \& Stubbe fc, Kendall fc). Doing RP is clearly directly relevant here. 
Holmes, J., \& Marra, M. (2004). Relational practice in the workplace: Women's talk or gendered discourse? Language in Society, 33(3), PREPRINT.

However, while recognising the inadequacy or invidiousness of essentialised, dichotomous conceptions of gender, it must be acknowledged that in everyday life it really is often the case that gender is 'essential'. As Holmes \& Meyerhoff (fc a) point out: We can argue about whether people ought to see male and female as a natural and essential distinction, and we can point to evidence showing that all social categories leak. However, that has not changed the fact that gender as a social category matters. There is extensive evidence to suggest that gender is a crucial component of people's social world; many people really do find it essential to be able to pigeon-hole others into the normative, binary set of female male, and they find linguistic or social behaviours which threaten the apparent stability of this 'essential' distinction extremely disturbing. Thus, they censure women (overtly or indirectly) for behaviour that is a typically associated with males, they beat up transvestites, they pathologize or murder homosexuals.

This raises the important theoretical issue of why and how RP has become associated with women. RP is clearly not just women's work, but nonetheless it is work strongly associated with women rather than men. As described by Fletcher, and illustrated in our analysis above, RP is "gendered" work, it is "feminine" behavior. It is support work, oriented to people's face needs, to preserving their relationships with others and their dignity and self esteem.

As Fletcher (1999: 133) says "Relational practice is not gender-neutral behaviour. It is behaviour that engages deeply held gender identities and beliefs", and Eckert \& 
Holmes, J., \& Marra, M. (2004). Relational practice in the workplace: Women's talk or gendered discourse? Language in Society, 33(3), PREPRINT.

McConnell-Ginet (fc: 11) make a similar point: "Traditional women's jobs are in the service sector, and generally involve nurturing and support roles ...Wherever they are, women are expected more than men to remember birthdays, soothe hurt children, offer intimate understanding". So, even when undertaken by men, RP is perceived as feminine behaviour because of the pervasive gender stereotypes which imbue our culture (see Cameron fc, Talbot fc).

But this is clearly not the whole story. Our analyses suggest that there may be other distinctly unfeminine ways of doing RP. Focussing on the functions of RP, as identified in the three criteria specified at the outset of this paper, our research suggests that there are alternative off-record means of "creating team", for example, while also furthering achieving workplace objectives. While some communities of practice (those identified as more "feminine" in interactional style) tend to adopt the kinds of strategies discussed by Fletcher, and illustrated in detail in this paper, other more "masculine" communities of practice appear to prefer different ways of doing RP. These orientations emerged in particular in our studies of humour, an indisputably off-record discourse strategy in the workplace, but they were also evident in other aspects of workplace interaction.

In a detailed analysis of the management style of two women in contrastingly "gendered" workplaces, for example, one a government department and the other a soap factory, Holmes and Stubbe (fc) showed that while both women used relational strategies in their interactions (as well as more assertive and directive strategies where appropriate), there were nevertheless noticeable differences in their preferred interactional styles. In the 
Holmes, J., \& Marra, M. (2004). Relational practice in the workplace: Women's talk or gendered discourse? Language in Society, 33(3), PREPRINT.

workplace regarded as more "feminine" in its overall style of interaction, there was "a marked orientation towards collaborative styles and processes of interaction, together with a high level of attention to the interpersonal dimension" and a preference by the manager for "less direct, more linguistically polite strategies to achieve her goals in a consensual way". (Holmes \& Stubbe fc). Self-deprecating humour was used to reestablish good relations after the manager had been particularly directive. In the factory team, a more "masculine" community of practice, the team leader generally adopted more direct, authoritarian and forceful strategies to communicate with her team as a whole, including ungarnished criticism when the team failed to meet its targets. The humour in this workplace was very different from that in the "feminine" workplace: it was very frequent and much more sparky, contestive and aggressive, with a good deal of jocular abuse, good-humoured insult, and sarcastic comment (see Stubbe 1999, 2000).

These analyses suggest an alternative perspective on the issue of RP as a gendered phenomenon. It seems at least plausible that different communities of practice develop not only distinctive ways of handling humour in the workplace, but also different ways of doing RP. We are not referring here to differences in the distribution of particular RP strategies - such differences are inevitable - but rather to the more fundamental issue of possible differences in what the researcher "counts" as RP in different workplaces.

Most of the teams in the workplaces in which we recorded provided evidence of the feminised discourse of RP that we have exemplified above: people skilfully made use of subtle and off-record strategies to "create team" and to pay attention to face needs, and to 
Holmes, J., \& Marra, M. (2004). Relational practice in the workplace: Women's talk or gendered discourse? Language in Society, 33(3), PREPRINT.

reduce face threat, and manage potential conflict, while furthering their work team's objectives. The teams in some workplaces, however, presented rather different patterns. In one team (which we will label Maxiteam) there was scarcely any conventional small talk, for instance, and the humour was predominantly aggressive and sarcastic, ie. directly face threatening rather than supportive or attenuating in its effect. And as mentioned, above, in the factory team, the humour consisted predominantly of aggressive jocular insults and verbal abuse. Both these communities of practice were perceived as very "masculine" in their style of interaction. Their workplace discourse was often confrontational and aggressive, with frequent challenges and disagreements. ${ }^{13}$ How, if at all, was RP being achieved in such workplaces?

While some conventionally gendered relational work did occur in these more "masculine" communities of practice, it was infrequent and stood out in our analyses as untypical. Indeed it was "marked" as "feminine" for participants too, as illustrated in example $8 .{ }^{14}$ In this aggressively "masculine" community of practice, Callum is jokingly criticised for unmanly, voluntarily "communicative" behavior.

\section{Example 8 Talking to end-users}

Context: 6 men in regular meeting of a project team in a large commercial organization. Callum's colleagues pretend to be horrified that he has actually talked face-to-face with clients

1 Barr: but we can we can kill this /particular= 
Holmes, J., \& Marra, M. (2004). Relational practice in the workplace: Women's talk or gendered discourse? Language in Society, 33(3), PREPRINT.

2 Marc: /well yepl

3 Barr: =action $\backslash$ point

4 Marc: you can kill this particular action point

5 Barr: and you /guys $\backslash$

6 Call: /arel you sure +++ I took the opportunity

$7 \quad$ of talking with some of the users

8 Barr: what again? [laughs] /[laughs]।

9 Marc: /not again what are you doing talking to them।

10 Barr: [laughs]: go on Callum come on

Barry and Marco suggest a particular proposed action be killed, i.e. dropped. Callum protests, pointing out that the proposed action emerged from his discussions with users. Barry and Marco then proceed to deride Callum's complaint, ridiculing the notion that he should actually talk, ie. verbally communicate face-to-face, with clients. This, they suggest, is inappropriate behaviour, with the strong implication that it entails unacceptably "feminine" approach. This provoked us to re-consider the notion of RP, as defined by Fletcher. The "small talk" of the Maxiteam members, for example, which occurred at the beginning and end of their meetings was consistently work-focussed. Though it was off-record and off-topic in terms of the agenda of the current meeting (see Holmes 2000b), it was generally related to some other aspect of the teams' work. In the six meetings of this team that we videotaped in full, there is scarcely a single topic that is not directly related to some aspect of the team's work. And the humour of this group was 
Holmes, J., \& Marra, M. (2004). Relational practice in the workplace: Women's talk or gendered discourse? Language in Society, 33(3), PREPRINT.

consistently negative and face threatening. Over $90 \%$ of the humorous comments which occurred in one meeting, for instance, were sarcastic and negative jibes, intended to put down the addressee or deflate them. ${ }^{15}$ This was clearly the team's preferred interactional style, and for this group, we suggest, this was their way of doing RP. Their contestive humour functioned to "create team" - participants often competed to out-do each other and "top" the previous witty comment - and its focus was generally closely related to their workplace objectives and goals: eg lambasting an individual for failing to meet their targets, ridiculing someone for overly meticulous attention to detail, accusing someone of claiming too much, and so on (Holmes 2000c, Holmes \& Marra 2002)

Clearly what happens in such communities of practice is that those who "can't hack it" leave. One person commented, for instance, that the interactional style of the Maxiteam team was so uncomfortable for him that he applied to move to another team. In her study of an Australian bank, Beck (1999: 205) notes that "a considerable number of senior women managers despaired at the ongoing masculinised culture ...one woman referred to the Bank's 'macho' culture which had driven her to leave her post after only eight months". It seems worth considering, then, how discursive strategies which appear so alienating to some employees, may form the underpinning for or constitute the bonds of strong working relationships between others. In Fletcher's account, RP fosters workplace relationships through behaviours associated with women, behaviours conventionally regarded as polite, facilitative and feminine. Consideration of ways of creating team, while also furthering workplace goals, in more "masculine" workplaces suggest that the term RP may need to be de-gendered. This proposal also has interesting implications for 
Holmes, J., \& Marra, M. (2004). Relational practice in the workplace: Women's talk or gendered discourse? Language in Society, 33(3), PREPRINT.

relational theory, which assumes that the primary function of RP is to foster interpersonal relations in order to promote personal growth (eg. Gilligan 1982, Miller 1986, Miller \& Stiver 1997). If alternative forms of RP are recognised, the answer to the question of whether they have the same positive effects on the individual is by no means obvious. Indeed, it is conceivable that, however useful in terms of engendering team spirit and whipping up energy for the benefit of the project, more contestive and competitive manifestations of RP may have distinctly negative effects on individuals, such as undermining self-confidence, inflicting emotional pain, and causing alienation from the work team, if not the organisation.

\section{Conclusion}

Using a stringent definition of relational practice, this paper has explored and illustrated the multifunctional nature of workplace discourse, focussing particularly on the varied ways in which workplace discourse contributes simultaneously to "creating team" and "preserving the workplace enterprise" (Fletcher 1999). Because RP is by definition realised by off-record, discounted and disvalued strategies, our examination of how RP is accomplished has also provided a means of demonstrating the ways in which discourse becomes "gendered" in the workplace. As Fletcher puts it, "women are relied on to be the carriers of relational responsibility in society" (1999: 15). RP, she suggests, is quintessentially "women's work"- invisible and unappreciated, yet positive in its intention of fostering behaviours that will assist the team to achieve their goals. 
Holmes, J., \& Marra, M. (2004). Relational practice in the workplace: Women's talk or gendered discourse? Language in Society, 33(3), PREPRINT.

Discourse strategies used to accomplish RP have been analysed along two dimensions: firstly, those oriented to "creating team" or constructing and maintaining positive workplace relationships; and secondly, strategies for "damage control" or avoiding conflict. Manifestations of the former include engaging in small talk and social talk, using humour to entertain and amuse others, and giving approval. The first and last of these strategies are generally regarded as more frequent in women's discourse, and there is also evidence that at least in some contexts, women use more humour than men. Strategies for "damage control" or avoiding conflict include attenuating disagreements, softening refusals, and hedging directives, and, again, these strategies are stereotypically associated with women's ways of talking. Our analysis has illustrated, however, that both sets of strategies were used by both men and women in the New Zealand workplaces we examined.

More importantly, however, we have provided detailed evidence of how these practices are "disappeared" or rendered invisible in workplace discourse. It is this which transforms them into stereotypical "women's work" or better "femininised discourse". RP is invisible and off-record relational work. (Indeed Fletcher claims that RP is not only overlooked, it is actively "disappeared" or erased because of its association with the feminine, and thus with soft rather than "hard" business practices (1999: 3)). Our examples have indicated how this process is accomplished - how RP often operates at the interstices of "real business", at the boundaries of meetings, in passing in the corridor, over lunch, and so on. ${ }^{16}$ It is this characteristic - its off-record status - that associates RP with feminine stereotypes. Like cooking, cleaning, shopping and washing, men can do it 
Holmes, J., \& Marra, M. (2004). Relational practice in the workplace: Women's talk or gendered discourse? Language in Society, 33(3), PREPRINT.

too, but the societal perception is that these are women's tasks or feminine gendered activities.

We have also suggested that the concept of RP may be too narrowly conceived, and that it may reflect a somewhat blinkered perspective on what "counts" as relational work. For some communities of practice it seem possible that contestive and aggressive interaction is an accepted and standard means of "creating team". When one of the effects of the interaction is to further workplace objectives, and the interaction is strictly off-record, there seems a prima facie case for including such interactional work as RP. However, the psychological implications of this very different kind of relational practice seem likely to contrast markedly with those described within relational theory. The range of ways of accomplishing RP in diverse communities of practice, and their effect on workplace relationships and structures, is clearly a challenging area for further research. 
Holmes, J., \& Marra, M. (2004). Relational practice in the workplace: Women's talk or gendered discourse? Language in Society, 33(3), PREPRINT.

\section{Notes}

${ }^{1}$ This paper is based on a Plenary paper presented at IGALA2, the second International Gender and Language Conference, held at Lancaster University in April 2002. Standard acknowledgement

${ }^{2}$ While this issue arises in the discussion below, we do not pursue it in depth in this paper. However, we note that the difficulty of maintaining boundaries between the different criteria, and the distinctiveness of the concept of relational practice vs other "relational" behaviours at work, is an issue that deserves further consideration.

${ }^{3}$ The parallels with Brown and Levinson's (1987) concepts of positive and negative face are obvious. Our purpose here is to elaborate these analytical dimensions in relation to workplace discourse.

${ }^{4}$ Holmes (2000b) explores in some detail the distribution, content and complex functions of small talk and social talk at work.

5 Transcription conventions are provided at the end. In order to facilitate reading, examples are sometimes slightly edited: eg by eliminating detail irrelevant to the point being illustrated (eg overlaps, detailed paralinguistic information).

${ }^{6}$ See Holmes (2000c) for a detailed discussion of the functions of humour in the workplace data we recorded.

${ }^{7}$ This example is discussed in more detail in Holmes (2000c)

${ }^{8}$ Unsurprisingly, there are many further unprintable terms for this important concept.

${ }^{9}$ Not all jocular insults serve this function of course (see Hay 1994, 1995, Stubbe 1999)

10 This example is taken from Holmes and Stubbe (2001) where is it analysed from a different perspective

${ }^{11}$ This claim is extensively documented in many of the articles in Holmes and Meyerhoff (fcr b).

${ }^{12}$ Chris's standard pseudonym in our data is Clara. 
Holmes, J., \& Marra, M. (2004). Relational practice in the workplace: Women's talk or gendered discourse? Language in Society, 33(3), PREPRINT.

${ }^{13}$ See Kuiper (1991) and Kiesling (2001) for instances of this kind of "masculine" discourse among New Zealand rugby players and US fraternity members

${ }^{14}$ This example is analysed in more detail in Holmes (fc).

${ }^{15}$ See Holmes and Marra (2002, ip) for examples.

${ }^{16}$ See also Holmes (2000b), Marra (fc). 
Holmes, J., \& Marra, M. (2004). Relational practice in the workplace: Women's talk or gendered discourse? Language in Society, 33(3), PREPRINT.

\section{Appendix}

Transcription conventions

$\begin{array}{ll}\text { YES } & \text { Capitals indicate emphatic stress } \\ \text { [laughs] : : } & \text { Paralinguistic features in square brackets, colons indicate start/finish } \\ + & \text { Pause of up to one second } \\ \ldots / \ldots \ldots l \ldots & \text { Simultaneous speech } \\ \ldots \text { /.......... } & \\ \text { (hello) } & \text { Transcriber's best guess at an unclear utterance } \\ - & \text { Incomplete or cut-off utterance } \\ \ldots & \text { Section of transcript omitted }\end{array}$

All names used in examples are pseudonyms. 
Holmes, J., \& Marra, M. (2004). Relational practice in the workplace: Women's talk or gendered discourse? Language in Society, 33(3), PREPRINT.

\section{References}

Beck, Dominique M. (1999). Managing discourse, self and others: Women in senior management positions. Unpublished $\mathrm{PhD}$ thesis. University of Western Sydney, Nepean.

Brown, Penelope \& Stephen C. Levinson (1987). Politeness: Some universals in language usage. Cambridge: Cambridge University Press.

Cameron, Deborah (forthcoming). Gender and language ideologies. In Janet Holmes \& Miriam Meyerhoff (eds.), Handbook of language and gender. Oxford: Blackwell.

Coates, Jennifer (1996). Women talk. Oxford: Blackwell.

Cox, Joe A., Raymond L.Read, \& Philip M.Van Auken (1990). Male-female differences in communicating job-related humor: An exploratory study. Humor 3, 3: 287-295.

Crawford, Mary (1995). Talking difference: On gender and language. London \& Thousand Oaks: Sage.

Crawford, Mary \& Diane Gressley (1991). Creativity, caring and context - women's and men's accounts of humor preferences and practices. Psychology of women quarterly 15, 2: 217-231.

Eckert, Penelope \& Sally McConnell-Ginet (forthcoming). Language and gender: The social construction of meaning. Cambridge: Cambridge University Press.

Fletcher, Joyce K. (1999). Disappearing acts. Gender, power, and relational practice at work. Cambridge, Mass.: MIT Press.

Gilligan, Carol (1982). In a different voice. Cambridge, Mass.: Harvard University Press.

Goffman, Erving (1974). Frame analysis. New York: Harper and Row. 
Holmes, J., \& Marra, M. (2004). Relational practice in the workplace: Women's talk or gendered discourse? Language in Society, 33(3), PREPRINT.

Hay, Jennifer (1994). Jocular abuse patterns in mixed-group interaction. Wellington working papers in linguistics 6: 26-55.

Hay, Jennifer (1995). Gender and humour: Beyond a joke. Unpublished MA Thesis, Victoria University of Wellington, Wellington, New Zealand.

Herbert, Robert K. (1990). Sex-based differences in compliment behavior. Language in society 19: 201-224.

Holmes, Janet (1988). Paying compliments: A sex-preferential positive politeness strategy. Journal of pragmatics 12,3: 445-465.

Holmes, Janet (1995). Women, men and politeness. London: Longman.

Holmes, Janet (2000a). Victoria University of Wellington's Language in the Workplace project: An overview. Language in the workplace occasional papers 1.

Holmes, Janet (2000b). Doing collegiality and keeping control at work: Small talk in government departments. In Justine Coupland (ed.), Small talk, 32-61. London: Longman.

Holmes, Janet (2000c). Politeness, power and provocation: How humour functions in the workplace. Discourse studies 2,2: 159-185.

Holmes, Janet (2000d). Women at work: Analysing women's talk in New Zealand workplaces. Australian review of applied linguistics (ARAL) 22, 2: 1-17.

Holmes, Janet (forthcoming). Sharing a laugh: Pragmatic aspects of humour and gender in the workplace. To appear in Helga Kotthoff (ed.), Journal of pragmatics: Special issue on humour).

Holmes, Janet \& Meredith Marra (2001). The place of identity construction in workplace narratives. NZ Linguistics Society Conference, University of Canterbury, Christchurch, 30 August-1 September 2001. 
Holmes, J., \& Marra, M. (2004). Relational practice in the workplace: Women's talk or gendered discourse? Language in Society, 33(3), PREPRINT.

Holmes, Janet \& Meredith Marra (2002). Over the edge? Subversive humour between colleagues and friends. Humor 15,1: 1-23.

Holmes, Janet \& Meredith Marra (in press). Having a laugh at work: How humour contributes to workplace culture. Journal of pragmatics.

Holmes, Janet, Meredith Marra \& Louise Burns (2001). Women's humour in the workplace: A quantitative analysis. Australian journal of communication 28,1: 83108.

Holmes, Janet \& Miriam Meyerhoff (forthcoming a). Different voices, different views: An introduction to current research in language and gender. In Janet Holmes \& Miriam Meyerhoff (eds.), Handbook of language and gender. Oxford: Blackwell.

Holmes, Janet \& Miriam Meyerhoff (eds.) (forthcoming b). Handbook of language and gender. Oxford: Blackwell.

Holmes, Janet \& Maria Stubbe (2001). Managing conflict at work. Paper presented at Colloquium on Researching the Discourse of Workplace and Professional Settings, AAAL 200, St Louis, USA.

Holmes, Janet \& Maria Stubbe (forthcoming). "Feminine" workplaces: Stereotype and reality. In Janet Holmes \& Miriam Meyerhoff (eds.), Handbook of language and gender. Oxford: Blackwell

Johnson, Donna M. \& Duane H. Roen (1992). Complimenting and involvement in peer reviews: gender variation. Language in society 21,1: 27-57.

Kendall, Shari (forthcoming). Creating gendered identities at work and home. In Janet Holmes \& Miriam Meyerhoff (eds.), Handbook of language and gender. Oxford: Blackwell

Kiesling, Scott (2001). "Now I gotta watch what I say": Shifting constructions of gender and dominance in discourse. Journal of linguistic anthropology 11,2: 250-273. 
Holmes, J., \& Marra, M. (2004). Relational practice in the workplace: Women's talk or gendered discourse? Language in Society, 33(3), PREPRINT.

Kuiper, Koenraad (1991). Sporting formulae in New Zealand English: Two models of male solidarity. In Jenny Cheshire (ed.), English around the world, 200-209. Cambridge: Cambridge University Press.

Lakoff, Robin (1975). Language and woman's place. New York: Harper and Row.

Lenk, Uta (1998). Discourse markers and global coherence in conversation. Journal of pragmatics 30,2: 245-257.

Marra, Meredith (forthcoming). Decisions in New Zealand business meetings. Unpublished $\mathrm{PhD}$ thesis, Victoria University of Wellington, Wellington, New Zealand.

Miller, Jean B. (1986). Towards a new psychology of women. Boston: Beacon Press.

Miller Jean B. \& I. Stiver (1997). The healing connection. Boston: Beacon Press.

Schiffrin, Deborah (1987). Discourse markers. Cambridge: Cambridge University Press.

Stubbe, Maria (1998). Researching language in the workplace: A participatory model. Proceedings of the Australian linguistics society conference Brisbane University of Queensland July 1998. http://english.uq.edu.au/linguistics/als/als98/.

Stubbe, Maria (1999). Just joking and playing silly buggers: Humour and teambuilding on a factory production line. Paper presented at NZ Linguistics Society Conference, Massey University, 24-26 November 1999.

Stubbe, Maria (2000). "Just do it ...!": Discourse strategies for 'getting the message across' in a factory production team. Proceedings of the Australian Linguistics Society Conference University of Western Australia September 1999. http://www.arts.uwa.edu.au/LingWWW/als99/.

Stubbe, Maria, Janet Holmes, Bernadette Vine \& Meredith Marra (2000). Forget Mars and Venus, let's get back to earth: Challenging stereotypes in the workplace. In 
Holmes, J., \& Marra, M. (2004). Relational practice in the workplace: Women's talk or gendered discourse? Language in Society, 33(3), PREPRINT.

Janet Holmes (ed.), Gendered speech in social context: Perspectives from gown \& town, 231-258. Wellington: Victoria University Press.

Talbot, Mary (forthcoming). Gender stereotypes: Reproduction and challenge. In Janet Holmes \& Miriam Meyerhoff (eds.), Handbook of language and gender. Oxford: Blackwell 